\title{
A fast fluorimetric assay (FFA) for the detection of saxitoxin in natural phytoplankton samples
}

\author{
G. Gerdts ${ }^{1, *}$, C. Hummert ${ }^{2}$, G. Donner ${ }^{3}$, B. Luckas ${ }^{2}$, C. Schütt ${ }^{1}$ \\ ${ }^{1}$ Marine Chemistry and Natural Products, Biologische Anstalt Helgoland at the Alfred Wegener Institute, \\ Kurpromenade, 27483 Helgoland, Germany \\ ${ }^{2}$ Deptartment of Biology and Pharamacy, Institute of Food Chemistry, Friedrich-Schiller-University Jena, \\ Dornburger Straße 24-29, 07743 Jena, Germany \\ ${ }^{3}$ Taxonomische Arbeitsgruppe, Forschungsinstitut Senckenberg, Wattenmeerstation Sylt, Alfred-Wegener-Institut, \\ Hafenstraße 43, 25992 List/Sylt, Germany
}

\begin{abstract}
A fast fluorimetric assay (FFA) for the detection of saxitoxins in plankton samples was compared with the analysis by high performance liquid chromatography (HPLC). The correlation between the results of the assay and those of the HPLC is significant for most of the carbamoyl saxitoxins. During research cruises to the Orkney Islands and the Firth of Forth (Scotland) in 1997 and 1998, samples of toxic Alexandrium spp. blooms were analyzed successfully by FFA and HPLC. Because the toxin pattern of toxic Alexandrium spp. mostly consists of highly fluorescent saxitoxins (like STX and GTX3), the assay can be applied for monitoring toxic Alexandrium spp. blooms and is suggested as a tool for future prewarning systems of paralytic shellfish poisoning (PSP) events.
\end{abstract}

KEY WORDS: Saxitoxin $\cdot$ Paralytic shellfish poisoning $\cdot$ PSP $\cdot$ Fast fluorimetric assay Resale or republication not permitted without written consent of the publisher

\section{INTRODUCTION}

Paralytic shellfish poisoning (PSP) events in Europe are usually associated with blooms of toxic dinoflagellates of the genus Alexandrium spp. (Hallegraeff 1995, Elbrächter \& Schnepf 1996). Alexandrium spp. blooms frequently occur in shallow salt ponds, coastal bays and large estuaries, but also in open coastal waters (see Anderson 1998).

The causative agents of PSP are mainly highly toxic carbamoyl saxitoxins (STX), but also N-sulfocarbamoyl toxins which can be hydrolyzed to carbamate toxins by enzymes in human digestive glands or during preservation steps in the food industry (Luckas 1992). All congeners bind to Site 1 on the voltage-dependent sodium channel of neurons and inhibit neurotransmission. No antidote is known.

*E-mail: ggerdts@awi-bremerhaven.de
For economical reasons, most monitoring of PSP events is normally concentrated on the chemical analysis of shellfish samples, not on the causative organisms. This monitoring is performed by high performance liquid chromatography (HPLC) analysis (Sullivan et al. 1985, Hummert et al. 1997) and/or by biological testing methods (e.g. mouse test; AOAC 1990) according to procedures laid down in national or international directives. The range of acceptable thresholds of PSP in the edible parts of molluscs is 40 to $80 \mu \mathrm{g}$ STXequiv. per $100 \mathrm{~g}$ of mollusc meat in Europe and the USA (van Egmond et al. 1992). Fishing areas are closed until levels of saxitoxins fall below the threshold values.

In contrast, during phytoplankton monitoring programs, usually no efforts are made to detect or measure PSP directly in water samples. Here the quantification of Alexandrium spp. is done via microscopic counts ('Utermöhl counts'; Hasle 1978), but a valid judgement of whether toxic Alexandrium spp. are present or not can only be achieved by combining HPLC and Utermöhl counts. Unfortunately HPLC as well as 
microscopic counts are very time-consuming and expensive processes or, in the case of HPLC, require expensive equipment.

In 1975, Bates \& Rapaport described a simple fluorimetric method for the measurement of saxitoxins in shellfish samples whereby the nonfluorescent saxitoxin molecule is oxidized to a fluorescent purinederivative by $\mathrm{H}_{2} \mathrm{O}_{2}$ treatment. Despite its simplicity, the method has never been applied to plankton samples or dinoflagellate cultures. In recent years, more sensitive or detailed methods like HPLC (Sullivan et al. 1985), the MNB (Mouse Neuroblastoma)-test (Kogure et al. 1988), an ELISA (enzyme-linked immunosorbent assy; Chu \& Fan 1985) or a receptor assay (Vieytes et al. 1993) have replaced the fluorimetric assay. Nevertheless, a simple, cheap and fast detection method for saxitoxin is needed, especially for ecological studies of bloom dynamics of toxic Alexandrium species. Despite the importance of these toxic dinoflagellates, such studies are remarkably few and the complexeties of these blooms in coastal or estuarine systems are far from understood (Anderson 1998).

The objective of the research described herein was to develop a simple and fast assay for the detection of saxitoxin in algal cultures and natural plankton samples based on the fluorimetric method published by Bates \& Rapaport (1975).

\section{MATERIALS AND METHODS}

Algal cultures. Dinoflagellate cultures (Alexandrium fundyense CCMP1719, A. tamarense 57OK1K, A. tamarense CCMP115 and Prorocentrum micans ME04) were kindly provided by M. Elbrächter (Senckenberg Institute, Germany) and cultivated in F/2 medium (Guillard 1975 ) at $18^{\circ} \mathrm{C}$ and a $12: 12 \mathrm{~h}$ light:dark regime. Algal cells were harvested by filtration on glassfibre filters (Whatman GF/C) or by centrifugation.

Investigation area. Natural plankton samples were taken during Alexandrium spp. blooms on 2 research cruises with the RV 'Heincke' (13 to 24 May 1997, Cruise 1; 13 May to 1 June 1998, Cruise 2) from different locations around the Orkney Islands and the Firth of Forth (Scotland) using a rosette sampler. To estimate the extent of the blooms, samples were taken on northsouth or east-west transects during both cruises and during 2 drifting experiments east of the Firth of Forth and east of the Orkney Islands on Cruise 2.

Water sampling. Water samples from various depths from the surface to a maximum of $50 \mathrm{~m}$ were collected with a rosette water sampler with 121 bottles equipped with a CTD profiler for hydrographic measurements of conductivity, temperature and pressure and sensors for the determination of chlorophyll fluorescence and light.
During the daytime, up to 4 stations were sampled. To concentrate dinoflagellate biomass, water samples (3 to 5 l) were filtered through $47 \mathrm{~mm}$ glassfibre filters (Whatman GF/C) or passed through $50 \mathrm{~mm}$ nylonmesh filters (20 $\mu \mathrm{m}$ mesh size). Due to the higher filtration-capacity and speed of the nylon-mesh, these filters were used in addition to the glassfibre filters during drifting experiments to cope with the increased sample numbers. Samples were taken in duplicate in 1997. One filter was extracted and analyzed for saxitoxins on board by HPLC (see later subsection), the other was stored at $-20^{\circ} \mathrm{C}$ until further analysis in our shore-based laboratory by fast fluorimetric assay (FFA). In 1998, parallel samples were extracted and analyzed simultaneously by FFA and HPLC on board.

Extraction. All samples were extracted with 1 to $2 \mathrm{ml}$ of $0.03 \mathrm{~N}$ acetic acid in reaction vials and sonicated for $1 \mathrm{~min}(60 \mathrm{~W})$. Cellular debris and/or filter fragments were removed by centrifugation $(12000 \times g$ in shorebased laboratory; $2980 \times g$ on board ship). Each supernatant was transferred to a new reaction vial and stored at $-20^{\circ} \mathrm{C}$ until analysis by HPLC and FFA (see next subsection). For HPLC, extracts were passed through an $0.45 \mu \mathrm{m}$ nylon filter before analysis.

Fast fluorimetric assay. For the FFA, $100 \mu \mathrm{l}$ of each extract (phytoplankton- or dinoflagellate-culture samples), standard (STX; obtained from Sigma) or blank solution (0.03 $\mathrm{N}$ acetic acid), respectively, was mixed with $400 \mu \mathrm{l}$ of periodic acid solution (50 mM periodic acid, $4 \% \mathrm{v} / \mathrm{v} \mathrm{NH}_{4} \mathrm{OH}$ ) and incubated for $15 \mathrm{~min}$ at $50^{\circ} \mathrm{C}$. After incubation the reaction mixture was neutralized with $500 \mu \mathrm{l}$ of $1 \mathrm{M}$ acetic acid and transferred to a cuvette. Reaction conditions and solutions were taken from the HPLC-procedure for the analysis of saxitoxins as described by Hummert et al. (1997). The FFA was performed in a Kontron SFM25 fluorimeter at an excitation wavelength of $333 \mathrm{~nm}$ and emission scans from 333 to $533 \mathrm{~nm}$ were acquired (2 nm steps). After data aquisition, relative fluorescence units (RFU) of the blank solution were subtracted from those of the standard or the extract, and the RFU at $390 \mathrm{~nm}$ was calculated using SFM25 controller software. In a second measurement set, emission scans were run from 250 to $600 \mathrm{~nm}$ while the excitation wavelength was increased from 250 to $500 \mathrm{~nm}$ in $10 \mathrm{~nm}$ steps. These experiments were performed to obtain an overview of the fluorescence of oxidized samples over a broader wavelength range, but not for quantification.

HPLC. HPLC was performed with an AS-4000 intelligent autosampler and an L-6200 A intelligent pump (both from Merck/Hitachi), an RF 551 fluorescence detector (Shimadzu), an D-6000 HPLC-Manager (Merck/ Hitachi), a $1 \mathrm{ml}$ CRX 390 post-column reaction-unit (Pickering Laboratories) and a $250 \times 4.6 \mathrm{~mm}$ i.d. column packed with $5 \mu \mathrm{m}$ Supelcosil-C18 DB (Supelco 
No. 58355). Chromatography was performed as described recently by Hummert et al. (1997). The PSP toxins were separated at a C18-HPLC column, derivatized using a post-column derivatization system with periodic acid for oxidation, and the derivatization products detected in a fluorescence detector.

Toxin standards of STX, NeoSTX, GTX1, GTX2, GTX3 and GTX4 were purchased from the National Research Council Canada, Marine Analytical Chemistry Standards Program (NRC-PSP-1B), Halifax, Nova Scotia, Canada; these contained also minor, unquantified, traces of dcGTX2 and dcGTX3. dc-STX was provided by the European Commission (BCR; The Community Bureau of Reference, Brussels) for use as standard during an intercalibration exercise in 1995 and 1996.

The PSP toxins were identified by comparing chromatograms obtained from sample extracts with those resulting after injection of standard solutions containing GTX1 to GTX4, NeoSTX and STX. Quantification of PSP contents was carried out by comparing peak heights in chromatograms of sample extracts with corresponding calibration graphs (Hummert et al. 1997). In some samples, $\mathrm{N}$-sulfocarbamoyl toxins were detected by double injection, as previously described (Hummert et al. 1997). Briefly, N-sulfocarbamoyl toxins are converted into the related carbamoyl toxins (B1 to STX, B2 to NeoSTX, C1 to GTX2, C2 to GTX3, C3 to GTX1 and C4 to GTX4) when hydrochloric acid is applied. They can be identified and quantified by the
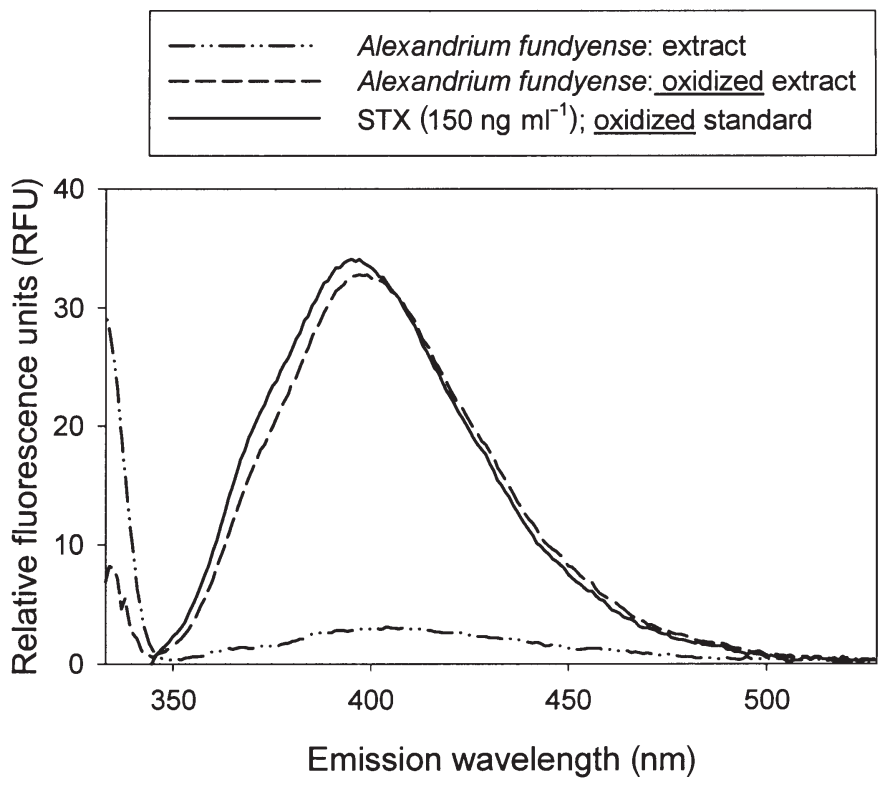

Fig. 1. Alexandrium fundyense. Emission scans (333 to $533 \mathrm{~nm}$, step size $2 \mathrm{~nm}$; fixed excitation wavelength $333 \mathrm{~nm}$ ) of an oxidized STX standard solution (150 $\left.\mathrm{ng} \mathrm{ml}^{-1}\right)$ and oxidized and non-oxidized extracts of the toxic dinoflagellate increases in peak heights in chromatograms of extracts before and after hydrolysis. Toxicity was calculated using the values for the relative toxicity (Sullivan et al. 1985) and expressed in ng STXequiv. ${ }^{-1}$.

The detection limits for all PSP toxins were the same as those used in a recent study (Hummert et al. 1997).

\section{RESULTS}

\section{STX standard and dinoflagellate cultures}

STX standard solutions showed an increase in fluorescence after oxidation (Fig. 1). The nonfluorescent saxitoxin molecule was oxidized to a fluorescent purine derivative.

Like STX standards, extracts of toxic Alexandrium fundyense or A. tamarense also displayed an increase in fluorescence at the $390 \mathrm{~nm}$ excitation wavelength after oxidation; emission scans of oxidized and unoxidized extracts of $A$. fundyense are shown in Fig. 1. In contrast, oxidized extracts of the dinoflagellate Prorocentrum micans, which served as a negative control, never showed an increase in fluorescence in this range of the emission scan. In a second set of experiments, a broader emission wavelength range was used (250 to $600 \mathrm{~nm}$ ) while the excitation wavelength was increased from 250 to $500 \mathrm{~nm}$ in $10 \mathrm{~nm}$ steps. Fig. 2 shows contour plots of RFU in respect to the acquired emission and excitation wavelength for an oxidized STX standard and oxidized A. tamarense and P. micans extracts. Again, high fluorescence values in the expected wavelength range, with a maximum fluorescence near $333 \mathrm{~nm}$ (excitation) and $390 \mathrm{~nm}$ (emission), were displayed by the oxidized STX standard solution and the extract of the toxic $A$. tamarense OK1K, but not by the oxidized extracts of non-toxic $A$. tamarense CCMP115 and P. micans (Fig. 2).

\section{Comparison of FFA, HPLC and field results}

Because of the increasing availability of various commercial PSP toxin standards it was possible to compare HPLC results for a number of carbamoyl, decarbamoyl and $\mathrm{N}$-sulfocarbamoyl saxitoxins with those of the FFA (as total fluorescence) by linear regression analysis. The HPLC results will be discussed briefly in a future paper (Hummert et al. 2002). For comparison of FFA and HPLC, the sample volume was taken into account, and the saxitoxin content (HPLC) and the relative fluorescence units (FFA) were calculated per litre.

For 32 samples from Cruise 1 in 1997 (glassfibre filter-enriched biomass) and 124 samples from Cruise 2 in 1998 (54 glassfibre filter samples and 70 nylon-mesh 


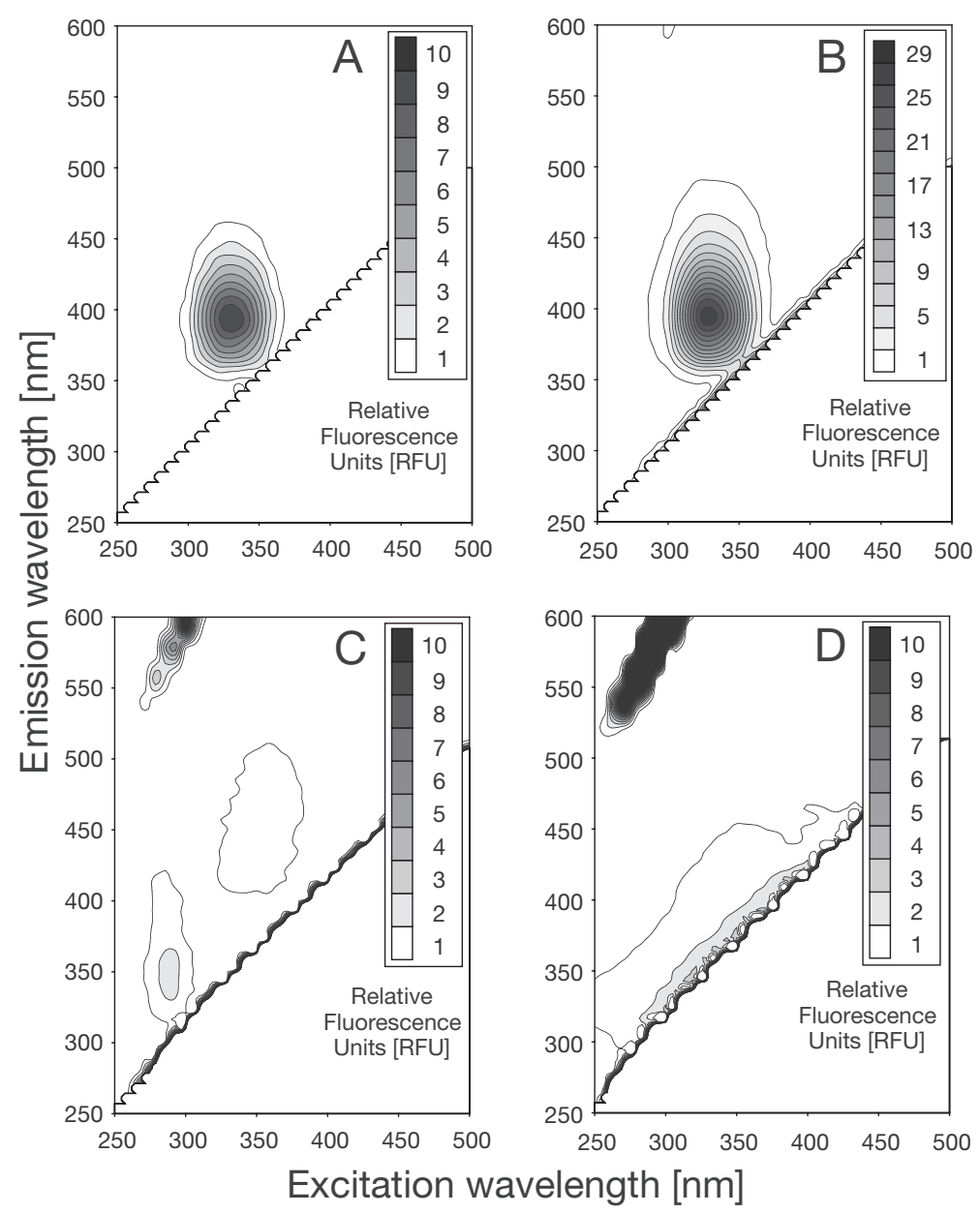

Fig. 2. Contour plots of relative fluorescence units (RFU) (emission wavelength 250 to $600 \mathrm{~nm}$, step size $2 \mathrm{~nm}$; excitation wavelength 250 to $500 \mathrm{~nm}$, step size $10 \mathrm{~nm}$ ). (A) oxidized STX standard solution (80 ng ml${ }^{-1}$ ); (B) oxidized extract of Alexandrium tamarense (57OK1K [toxic]); (C) oxidized extract of $A$. tamarense CCMP115 (non-toxic); (D) oxidized extract of Prorocentrum micans

samples), linear regressions were performed between RFU per litre as measured by the FFA and the concentration of carbamoyl and N-sulfocarbamoyl toxins as determined by HPLC (Table 1). N-sulfocarbamoyl toxins and decarbamoyl toxins were not determined on Cruise 1. Furthermore only a mixture of the carbamoyl toxins GTX1 and GTX2 was available as standard (GTX1/4) on this cruise. Decarbamoyl-toxins were not detected in any samples of Cruise 2. To compare the influence of the filters used (glassfibre filter and $20 \mu \mathrm{m}$ nylon mesh), the results of the linear regression analysis are displayed separately for the 2 filter types in Table 1, from which it is obvious that the fluorescence detected by FFA derived from all saxitoxin congeners present in the sample. Hence, the sum $(\Sigma)$ was also calculated, whereby the carbamoyl toxins as measured by HPLC were added after multiplication with individual fluorescence factors which take the different fluorescence of the oxidized molecules into account ( $\mathrm{Yu}$ et al. 1998).

The linear regression analysis of FFA and HPLC data showed significant correlations for all measured saxitoxins in samples of Cruise 1 (Table 1). The highest coefficients of determination $\left(\mathrm{r}^{2}\right)$ were calculated for GTX3 and $\Sigma$ (0.901 and 0.900, respectively). In respect to the samples of Cruise 2, GTX3 again displayed a high $\mathrm{r}^{2}(0.932)$ for the glassfibre filter samples but a lower $r^{2}$ for the nylon-mesh samples (0.504). For $\Sigma$, an $\mathrm{r}^{2}$ of 0.96 and 0.70 was calculated for glassfibre filter and nylon-mesh samples, respectively. Significant correlations could be calculated for all carbamoyl and $\mathrm{N}$-sulfocarbamoyl toxins in samples from Cruise 2 with the exceptions of B1 and B2 (glassfibre filters but not nylon-mesh samples) and C4 and C1 (glassfibre filter but not nylon-mesh samples).

\section{DISCUSSION}

Bates \& Rapaport (1975) described the initial fluorimetric method for the measurement of saxitoxins in shellfish samples on which the FFA of this study is mainly based. Until now, this method has only been applied to the examination of shellfish samples, and in recent years has been replaced by more sensitive methods like HPLC (Sullivan et al. 1985), the MNB-test (Kogure et al. 1988), and ELISA (Chu \& Fan 1985) or a receptor assay (Vieytes et al. 1993). All these methods have the advantage of high sensitivity, but they also have the disadvantages of being labour-intensive, expensive and time-consuming. For these reasons, when performing ecological surveys or monitoring programs for toxic dinoflagellates, most studies have focused on Utermöhl counts and only small sample numbers have been analyzed for saxitoxins by HPLC (Reguera et al. 1991, Aune et al. 1995, Hummert et al. 2002).

We have shown that the results of a FFA are in good agreement with those of an HPLC analysis of concentrated plankton from field samples. The coefficients of determination were significant for all carbamoyl saxitoxins. Because all toxic Alexandrium species contain at least one of the fluorescent carbamoyl toxins, FFA should be suitable for those research studies in which only Utermöhl counts are usually performed. Compared to Utermöhl counts, the information as to whether saxitoxin-producing dinoflagellates are present in a sample will be available after 30 min of analysis compared to the necessary settling time for cells in 
Table 1. Comparison of the fast fluorimetric assay with HPLC. Results of linear regression of relative fluorescence units versus carbamate-, decarbamoyl- and N-sulfocarbamoyl-saxitoxin content of extracted plankton samples determined by HPLC $\left(1^{-1}\right)$. $\mathrm{r}^{2}$ : coefficient of determination; p: probability; n: number of samples; ${ }^{*}$ : not determined by HPLC ${ }^{* *}$ : not detected by HPLC

\begin{tabular}{|c|c|c|c|c|c|c|c|c|c|}
\hline \multirow[t]{3}{*}{ Saxitoxin } & \multirow{2}{*}{\multicolumn{3}{|c|}{$\begin{array}{c}\text { Cruise } 1(13.05-24.05 .97) \\
\text { Glassfibre filter }\end{array}$}} & \multicolumn{6}{|c|}{ Cruise $2(13.05-01.06 .98)$} \\
\hline & & & & \multicolumn{3}{|c|}{ Glassfibre filter } & \multicolumn{3}{|c|}{ Nylon mesh } \\
\hline & $\mathrm{r}^{2}$ & $\mathrm{p}$ & $\mathrm{n}$ & $\mathrm{r}^{2}$ & $\mathrm{p}$ & $\mathrm{n}$ & $\mathrm{r}^{2}$ & $\mathrm{p}$ & $\mathrm{n}$ \\
\hline \multicolumn{10}{|c|}{ Carbamoyl-saxitoxins } \\
\hline STX & 0.888 & $<0.0001$ & 32 & 0.916 & $<0.0001$ & 54 & 0.846 & $<0.0001$ & 70 \\
\hline NeoSTX & 0.868 & $<0.0001$ & 32 & 0.738 & $<0.0001$ & 54 & 0.920 & $<0.0001$ & 70 \\
\hline GTX1/4 & 0.873 & $<0.0001$ & 32 & $*$ & & & ${ }^{*}$ & & \\
\hline GTX1 & $*$ & & & ** & & & ** & & \\
\hline GTX2 & 0.641 & $<0.0001$ & 32 & 0.174 & 0.0017 & 54 & 0.195 & 0.0001 & 70 \\
\hline GTX3 & 0.901 & $<0.0001$ & 32 & 0.932 & $<0.0001$ & 54 & 0.504 & $<0.0001$ & 70 \\
\hline GTX4 & $*$ & & & 0.537 & $<0.0001$ & 54 & 0.832 & $<0.0001$ & 70 \\
\hline$\Sigma$ & 0.900 & $<0.0001$ & 32 & 0.960 & $<0.0001$ & 54 & 0.706 & $<0.0001$ & 70 \\
\hline \multicolumn{10}{|c|}{ Decarbamoyl-saxitoxins } \\
\hline deSTX & * & & & ** & & & ** & & \\
\hline dcGTX 2 & * & & & ** & & & $* *$ & & \\
\hline dcGTX 3 & * & & & ** & & & $* *$ & & \\
\hline \multicolumn{10}{|c|}{ N-sulfocarbamoyl-saxitoxins } \\
\hline B1 & * & & & 0.000 & 0.9461 & 54 & 0.317 & $<0.0001$ & 46 \\
\hline B2 & * & & & 0.001 & 0.8262 & 54 & 0.317 & $<0.0001$ & 46 \\
\hline $\mathrm{C} 1$ & * & & & 0.716 & $<0.0001$ & 54 & 0.634 & $<0.0001$ & 46 \\
\hline $\mathrm{C} 2$ & * & & & 0.550 & $<0.0001$ & 54 & 0.704 & $<0.0001$ & 46 \\
\hline $\mathrm{C} 3$ & * & & & $* *$ & & & $* *$ & & \\
\hline $\mathrm{C} 4$ & * & & & 0.000 & 0.9769 & & 0.021 & 0.3375 & 46 \\
\hline
\end{tabular}

Utermöhl chambers of up to $2 \mathrm{~d}$. Because of the possible high sample-throughput of the FFA in conjunction with the high filtration capacity and speed of nylon mesh, it should be possible to examine the diurnal vertical migration of toxic Alexandrium spp. by this simple method during future on board surveys. Although the HPLC procedure is more sensitive than the FFA $(\sim 10 \mu \mathrm{l}$ of the extract is analyzed by HPLC, $100 \mu \mathrm{l}$ by FFA), this disadvantage can easily be overcome by filtering larger amounts of water. We usually filtered 3 to 51 of water on our cruises, which was sufficient for HPLC analysis and FFA. However, in respect to the phytoplankton samples examined, the detection limit of FFA for STX $\Sigma$ (the sum of all carbamoyl saxitoxins, see above) was in the range of $20 \mathrm{ng}$ per litre seawater.

The high correlation coefficients between the data from FFA and HPLC analysis in respect to most of the individual saxitoxins (even for those displaying low fluorescence when oxidized) can be explained as follows. The fluorescence of the oxidized sample should mostly be influenced by the saxitoxins STX, GTX3 and GTX2, with fluorescence factors of 1, 1.2 and 0.9 , respectively (Yu et al. 1998). Other saxitoxins like NeoSTX display much lower fluorescence factors (NeoSTX $=0.094)$. It can be assumed, therefore, that high coefficients of determinations calculated for saxitoxins with small fluorescence factors are not caused by 'real' fluorescence but by stable toxin patterns: the relationship between the saxitoxins is constant in the samples. On average, for samples taken during the drifting experiments and filtered onto nylon mesh, lower coefficients of determination were calculated (especially for GTX3) and high fluorescence values were recorded. This was not so for samples filtered onto glassfibre filters. When performing linear regression analysis after removing fluorescence values greater than $100 \mathrm{RFU} \mathrm{l}^{-1}$ from this data set, the coefficient of determination rose from 0.504 to 0.846 for GTX3, resulting in 0.883 for STX $\Sigma_{\text {; }}$ nevertheless, all linear regressions for saxitoxins with high fluorescence factors were significant (including also GTX3). A comparison of filter types revealed that glassfibre filters are more efficient for concentrating phytoplankton biomass.

Because of its easy sampling, extraction and measurement procedure, we suggest FFA be used as a simple tool for monitoring saxitoxin levels in PSP prewarning systems as well as for ecological surveys (EUROHAB 1999).

Acknowledgements. This research was part of the BMBF project TEPS (03F0161A).

\section{LITERATURE CITED}

Anderson DM (1998) Physiology and bloom dynamics of toxic Alexandrium species, with emphasis on life cycle transitions. NATO ASI Ser G Ecol Sci 41:29-48 
AOAC (Association of Official Analytical Chemists) (1990) Paralytic shellfish poison. Biological method. Final action. In: Hellrich K (ed) Official methods of analysis. 15th edn. Section 959.08. Association of Official Analytical Chemists, Arlington, VA, p 881-882

Aune, T, Dahl E, Tangen K (1995) Algal monitoring, a useful tool in early warning of shellfish toxicity? In: Aune T, Dahl E, Tangen K, Lassus P, Arzul G, Erard Le Denn E, Gentien P, Marcaillou Le Baut C (eds) Sixth International Conference on Toxic Marine Phytoplankton, Nantes (France), Oct 1993. Harmful marine algal blooms. Lavoisier, Paris, p 765-770

Bates HA, Rapaport H (1975) A chemical assay for saxitoxin, the paralytic shellfish poisoning. J Agric Food Chem 23: 237-239

Chu FS, Fan TSL (1985) Indirect enzyme-linked immunosorbent assay for saxitoxin in shellfish. J Assoc Off Anal Chem 68:13-16

Elbrächter M, Schnepf E (1996) Toxische Algen in der Nordsee. Dtsch Hydrogr Z, Suppl 6:37-44

EUROHAB (European Initiative on Harmful Algal Blooms) (1999) Harmful algal blooms in European marine and brackish waters. In: Graneli E, Codd GA, Dale B, Lipiatou E, Maestrini SY, Rosenthal H (eds) Energy, environment and sustainable development. EUR 18592, European Commision, Brussels

Guillard RRL (1975) Culture of phytoplankton for feeding marine invertebrates. In: Smith WL, Chanley MH (eds) Culture of marine invertebrate animals. Plenum Press, New York, p 26-60

Hallegraeff GM (1995) Harmful algal blooms: a global overview. In: Hallegraf GM, Anderson DM, Cembella AD (eds) Manual on harmful marine microalgae. IOC Manuals and Guides No. 33, UNESCO, Rome, p 1-22

Hasle GR (1978) Using the inverted microscope. In: Sournia A

Editorial responsibility: Otto Kinne (Editor),

Oldendorf/Luhe, Germany (ed) Phytoplankton manual. Monogr Oceanogr Methodol 6:191-196

Hummert C, Riutscher M, Reinhardt K, Luckas B (1997) Analysis of characteristic PSP profiles produced by Pyrodinium bahamense and several strains of Alexandrium using HPLC based on ion-pair chromatographic separation, post column oxidation and fluorescence detection. Chromatographia 45:312-316

Hummert C, Gerdts G, Schütt C, Luckas B (2002) PSP toxin content in algal blooms and molluscs in coastal waters around the Orkney Islands and the East Coast of Scotland. Proceedings on Harmful Algae, Ninth International Conference on Harmful Algal Blooms, Tasmania, p 16-19

Kogure K, Tamplin ML, Simidu U, Colwell RR (1988) A tissue culture assay for the tetrodotoxin, saxitoxin and related toxins. Toxicon 26:191-197

Luckas B (1992). Phycotoxins in seafood-toxicological and chromatographical aspects. J Chromatogr 624:439-456

Reguera B, Campos MJ, Fraga S, Marino J, Bravo I (1991) The monitoring of harmful algal blooms in Galicia (NW Spain). In: Fremy JM (ed) Proceedings of Symposium on Marine Biotoxins, Paris, p 217-223

Sullivan JJ, Wekell LL, Kentala LL (1985) Application of HPLC for the determination of PSP toxins in shellfish. J Food Sci 50:26-29

van Egmond HP, Speyers GJA, van den Top HJ (1992) Current situation on worldwide regulation for marine phycotoxins. J Natl Toxins 1:67-85

Vieytes MR, Cabado AG, Alfonso A, Louzao MC, Botana AM, Botana LM (1993) Solid-phase radioreceptor assay for paralytic shellfish toxins. Anal Biochem 211:87-93

Yu RC, Hummert C, Luckas B, Qian PY, Zhou MJ (1998) A modified HPLC method for analysis of PSP toxins in algae and shellfish from China. Chromatographia 48:671-676

Submitted: January 21, 2000; Accepted: October 16, 2001 Proofs received from author(s): March 11, 2002 